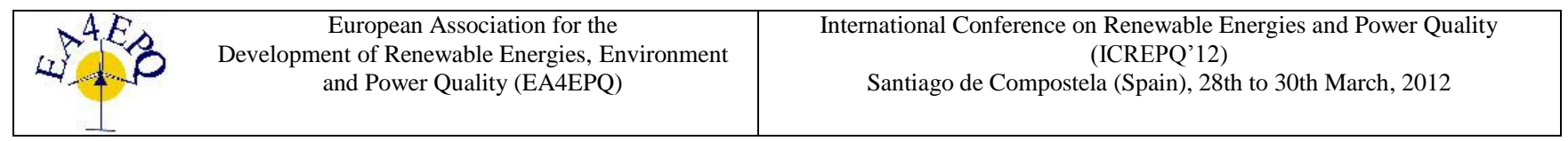

\title{
A reactor for rapid water disinfection in rural areas and post disaster situations
}

\author{
S. Ali Shah ${ }^{1}$, R. Saunders ${ }^{2}$ \\ ${ }^{1,2}$ Department of Physics \\ The University of the West Indies \\ St Augustine Campus - Trinidad \\ Phone/Fax number: (868) 6622002 Ext 82051/ (868) 662 9904, e-mail: shazaad.ali-shah@sta.uwi.edu, \\ ramsey.saunders@sta.uwi.edu
}

\begin{abstract}
.
Solar Disinfection (SODIS) is the method usually applied internationally to purifying water in rural areas when pipe borne water is not available. Using Poly Ethylene Terephtalate (PET) bottles the process takes 4 hours under the environmental conditions of Trinidad and Tobago. We have built and tested a portable reactor for decontamination on a larger scale than that possible with bottles. The active surface of this reactor is a coating of titanium dioxide nanoparticles on frosted glass or on a flexible plastic surface coated with glass ballotini of average diameter $0.5 \mathrm{~mm}$. The plastic surface is more suitable for use in rural areas and post disasters situations. In each case Titanium dioxide nanoparticles $(35 \mathrm{~nm})$ were deposited by a sedimentation process. E. coli contaminated water placed in the reservoir of the reactor was pumped over the active surface at a rate of $48 \mathrm{~L} / \mathrm{hr}$ while it was exposed to sunlight. E. coli degradation was rapid for the both surfaces, total elimination taking place within 10 to 30 minutes depending on the solar conditions. The photocatalytic effect of titanium dioxide in the presence of ultraviolet light is the main contributor to the observed decrease in bacterial concentration. Titanium dioxide absorbs ultraviolet light from short wavelengths up to $385 \mathrm{~nm}$ and is known to be effective in solar detoxification.
\end{abstract}

\section{Key words}

Titanium dioxide, reactor; disinfection, nanoparticles, photocatalyst.

\section{Introduction}

It is a well known fact that water covers about seventy percent $(70 \%)$ of the earth's surface. This can give us a false sense of security with water and its availability for our use. In reality $97 \%$ of the planet's water exists in the ocean in salty form. The Pacific Ocean contains $52 \%$ of this salt water, the Atlantic Ocean $25 \%$ and the Indian Ocean $20 \%$. The remaining $3 \%$ of the salt water is spread out in all the other oceans of the earth. [1]. Three (3) percent of the available water is fresh water. Of this two thirds exists as ice and is largely unavailable to humans. Thus less than $1 \%$ is accessible either as surface water or ground water for human usage [2].

As we advance into the $21^{\text {st }}$ century we are seeing the signs of a water crisis. In 1999 the United Nations Environment Programme (UNEP) had identified water shortage as one of the two most worrying problems for the new millennium, the other being global warming. Presently 1.1 billion people ( $18 \%$ of the world's population) do not have enough clean water to consume and 2.6 billion ( $42 \%$ of the world's population) do not have access to sanitary facilities making clean water less likely [3]. Sanitation coverage levels are the lowest in the Sub-Saharan Africa (36 percent) and South Asia (37 percent) regions [3]. It should therefore be of no surprise that there are over 2.2 million deaths annually from diseases associated to poor quality drinking wáter [4]. Of these $98 \%$ are from the developing world. A child under the age of five dies every twenty seconds.

The basic methods of producing safe drinking water are boiling, chlorination and reverse osmosis. These methods are not available to many impovished and rural areas as well as post disaster situations. Water contaminated with bacteria if consumed can lead to diarrhoea and other related illnesses which may often result in death [3].

Solar water disinfection or SODIS as it is commonly referred to is a process which can be made available for rural and impovished as well as post disaster situations. Inactivation of the microorganisms by UV-A radiation and thermal treatment after six (6) hours of exposure to sunlight can produce water that is safe for consumption. [5]. This method is rather lenghty. There is therefore a need to develop a simple purification system that would be much faster and yield larger volumes of purified water than that which is possible with SODIS.

The photocatalytic degradation of compounds using titanium dioxide $\left(\mathrm{TiO}_{2}\right)$ and ultraviolet light is a 
promising method for the purification of polluted water by advanced oxidative technique.

It is predicted that in the near future the photocatalytic methods will become the most effective methods in the purification of various kinds of household and industrial wastewater. This paper however will address the use of artificially contaminated water using the E.coli bacteria as the contaminant.

\section{Method}

The method involved the flow of artificially contaminated water over the active surface of a reactor. The water is subsequently tested for bacterial concentration.

\subsection{Growth media preparation}

Two media Nutrient Agar and Nutrient Broth were prepared to assist bacterial growth. The details of their preparation are as follows:

\subsubsection{Nutrient Agar preparation}

To $100 \mathrm{ml}$ of distilled water $2.8 \mathrm{~g}$ of Nutrient Agar powder (Oxoid) was added and thoroughly mixed according to the instructions by the product manufacturers. The solution obtained was then placed in an autoclave for 15 minutes at $121^{\circ} \mathrm{C}$. It was subsequently allowed to cool to $45^{\circ} \mathrm{C}$ in a laminar flow cabinet then poured into four large petri dishes $(12 \mathrm{~cm}$ diameter) and allowed to cool until it became jelly like in nature. This process was repeated once there was a need for the nutrient agar plates.

\subsubsection{Nutrient Broth preparation}

To $250 \mathrm{ml}$ of distilled water, $2 \mathrm{~g}$ of Nutrient Broth (Difco) was added and stirred. This flask was placed in an autoclave and heated for 15 minutes at $121^{\circ} \mathrm{C}$ forming the sterile growth medium for the E.coli colonies. Two $250 \mathrm{ml}$ flasks were prepared in this manner for each experimental run.

\subsubsection{Bacterial growth}

An agar slant (45 degree slope) containing pure E coli culture was used to streak a nutrient plate in a laminar flow cabinet following all the necessary precautions (General aseptic techniques). The plate was subsequently incubated at $35^{\circ} \mathrm{C}$ for 24 hours. Isolated colonies of $\mathrm{E}$ coli were transferred using a sterile loop to the nutrient broth. Three (3) loopfulls were transferred to each of the $250 \mathrm{ml}$ of broth. These flasks were then placed in an incubatorshaker (LabLine) which was set at $30^{\circ} \mathrm{C}$ and $175 \mathrm{rpm}$ and left for 24 hours to assist with bacterial growth. The nutrient broth gradually became turbid indicating bacterial growth. This was used as the source of water contaminant.
Fifty $\mathrm{ml}$ of the contaminated nutrient broth were added to and thoroughly mixed with 10 litres of distilled wáter. This mixture was allowed to stand for 1 hour to ensure equilibrium. This contaminated water was then added to the reservoir ensuring at all times that it was shielded from any light source.

\subsection{Bacteria detection system, Colilert 18}

This system was provided by IDEXX Laboratory. Testing samples were poured into sterilized $100 \mathrm{ml}$ bottles. The individually sealed sachet containing the reagent was added to this $100 \mathrm{ml}$ sample. The bottle was securely covered with the supplied cap and the mixture thoroughly agitated until the reagent was completely dissolved. This mixture was then poured into the Idexx Quanti-Tray trough and sealed with the specially supplied sealer. Each sealed tray was properly labeled and placed in an incubator oven set at $35^{\circ} \mathrm{C}$ for at least 18 hours.

\subsection{Reactor Design}

The $1 \mathrm{~m}^{2} \mathrm{TiO}_{2}$ reactor $(1.2 \mathrm{~m} \times 0.86 \mathrm{~m})$ is situated on the roof of the Natural Science building at the St Augustine Campus in Trinidad. The reactor consists of two glass plates mounted in an aluminum frame. They are separated by about $8.0 \mathrm{~cm} . \mathrm{TiO}_{2}$ is deposited on the lower plate, which is made of frosted glass. This is the "active" surface of the reactor. The upper plate is protective and consists of normal transparent clear glass. Both plates are supported by "channelings" on the inner perimeter of the aluminum frame. The supporting base consists of three sections, which can be easily dismantled making it very portable. The upper section has a deep recessed area to accommodate the reactor and built in locks to firmly secure it. The middle section (Figure 1) has adjustable stability pins at the corners to ensure stability of the entire structure. It has, in addition, two pivots at one end for attachment to the upper section and a centrally mounted car jack to permit elevation of the upper section, which carries the reactor. The lower section is the "foot" of the entire system. It contains a centrally mounted bearing to which the middle section is connected. This section permits rotation of the middle section about its axis for solar tracking.

\subsection{Coating the surface using the Sedimentation technique.}

To coat the active reactor plate with $\mathrm{TiO}_{2}$, the protective plate of the upper section was removed to expose the active reactor plate and the "sedimentation" method used. With this plate in a horizontal position, a suspension of $8 \mathrm{gm}$ of $\mathrm{TiO}_{2}$ in 2 litres of water was poured onto it.

\subsection{Water preparation technique}




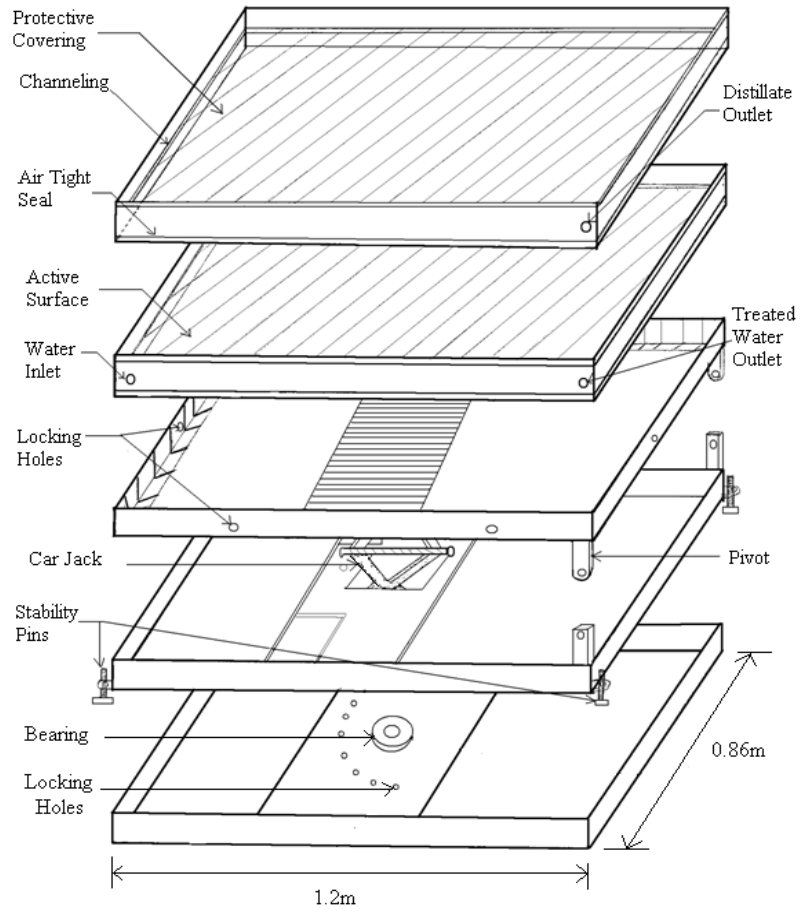

Figure 1. Detailed drawing of the reactor.

The $\mathrm{TiO}_{2}$ in the suspension was deposited on the frosted glass plate in about 12 hours and excess water removed by evaporation. This process was done in the laboratory using 2 halogen light sources and a domestic fan to assist with air circulation.

\subsection{Operation of the reactor}

In operation (see Figure 2) the upper section forms a sealed chamber, which can be inclined at an appropriate angle. The peristaltic pump (Ismatec) ensures a fixed flow rate of contaminated water to the top of the active reactor plate, which then flows under the influence of gravity to the collection point at the lower end of the plate. The flow rate can be varied to determine the optimum rate for photodegradation. The stainless steel reservoir can be isolated from the main reservoir by a valve, which therefore permits single runs or multiple runs.

The inlet port and both outlet ports are made of polyvinyl chloride (PVC). All areas with which the contaminated water will be in contact are constructed with either stainless steel, glass, PVC or non-reacting Tygon hosing.

The best flow pattern observed was with a pumping speed of 48 litres an hour. There was over $90 \%$ laminar flow coverage over the active surface with the water. The incline angle of 10 degrees was increased to 20 degrees to enhance gravity flow and increase the rate of run off from the active surface. This helped in allowing the water to run off at a faster rate and avoided it from collecting or pooling at the bottom part of the reactor.

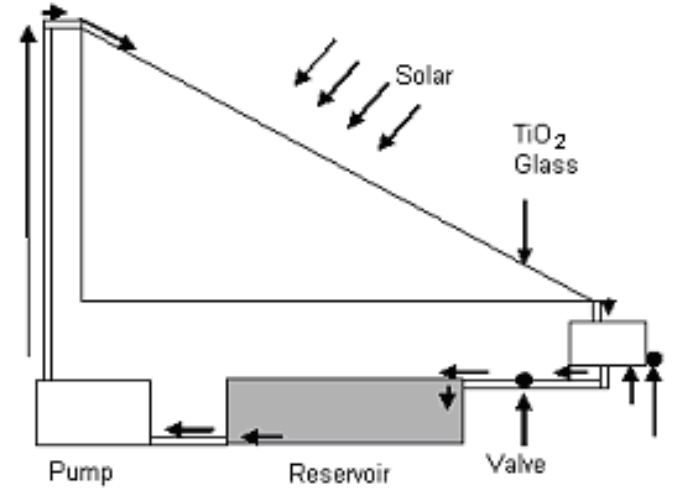

Figure 2. Schematic view of the $\mathrm{TiO}_{2}$ Fixed-Bed Solar Reactor

\subsection{Experimental details with frosted glass}

The protective cover was cleaned in order to allow maximum incoming insolation which was also a recorded parameter. The peristaltic pump was connected using a flow rate of $48 \mathrm{~L} / \mathrm{hr}$ and the incline angle of the reactor was also maintained. Samples for bacterial testing were taken every 5 minutes for the first 30 minutes, then every 10 minutes for the next 30 minutes, then every 20 minutes for the next hour and finally every 30 minutes for the third hour of testing. The reservoir temperature was also recorded at these intervals. Experiments were all performed on the roof of the Natural Science building of the University of the West Indies, Trinidad. Three were conducted in the day time and one in the night time

\subsection{Ballotini surface preparation.}

The pitted structure of the surface of the frosted glass reactor plate used in early experiments played a significant role in increasing its surface area and promoting good adhesion for the active titanium dioxide. In an attempt to provide a similar but more portable surface, glass ballotini with an average diameter of 0.5 $\mathrm{mm}$ were attached to a flexible plastic surface.

Water was allowed to flow over this new surface for approximately 24 hours to ensure that there was no trace of the attachment adhesive or unattached ballotini on it. The sedimentation process as indicated above was then applied to this new surface. Excess water was removed by natural evaporation in direct sunlight (i.e. air drying). When fully dried after approximately 12 hours, the flexible reactor surface was allowed to "bake" in natural sunlight for three days to increase the surface durability. Testing was also conducted on the new surface under four different insolation conditions. 


\section{Results and Discussion}

\subsection{Experiments using the coated frosted glass surface.}

\subsubsection{Insolation results}

Insolation plots for the first set of experiments performed on the roof are displayed together for comparison purposes. Of the four experiments, three, Experiment 1, Experiment 2 and Experiment 3 were carried out during the daytime. The fourth experiment, Experiment 4, was carried out during the night time. In the legend to Figures 3. 4 and 5, of the results, these experiments are referred to as Expt 1, Expt 2, Expt 3 and Expt 4 respectively. In Experiment 1 the maximum insolation was $1433 \mathrm{Wh} / \mathrm{m}^{2}$, the minimum $300 \mathrm{Wh} / \mathrm{m}^{2}$ and the average during the experiment $1058 \mathrm{Wh} / \mathrm{m}^{2}$ ( see Figure 3). In Experiment 2 the maximum was $1200 \mathrm{Wh} / \mathrm{m}^{2}$, the minimum $425 \mathrm{Wh} / \mathrm{m}^{2}$ and the average $733 \mathrm{Wh} / \mathrm{m}^{2}$. In Experiment 3 the respective values were $820 \mathrm{Wh} / \mathrm{m}^{2}, 645 \mathrm{Wh} / \mathrm{m}^{2}$ and 750 $\mathrm{Wh} / \mathrm{m}^{2}$. In Experiment 4 , the night time experiment, the insolation level was always $0 \mathrm{Wh} / \mathrm{m}^{2}$. Figure 3 also indicates that while in Experiment 2 there were several fluctuations between high and low insolation values, in Experiment 3, the insolation values were low throughout the experiment.

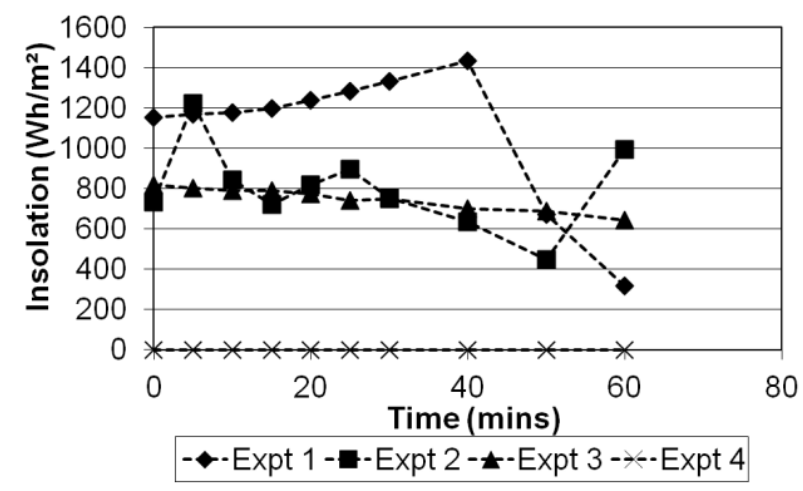

Figure 3. Graphs showing Insolation as a function of time.

\subsubsection{Reservoir temperatures}

Except for the night run, there was generally an increase in the temperature of the reservoir as well as the reactor with time. The final temperature of the reservoir in each case was $42^{\circ} \mathrm{C}$. This increase in temperature can contribute to a reduction in the bacterial concentration. However temperature increase cannot fully account for the data since SODIS must operate for 4 to 6 hours for complete disinfection [5]. Figure 4. shows the trends observed with the reservoir temperature for all experiments. No heating effect was observed on the "night time" experiment. The reservoir temperature recorded (Figure 4.) decreased by less than $1^{\circ} \mathrm{C}$ as the night became cooler during the experiment.

\subsubsection{Disinfection results}

Our results (Figure 5) indicate that complete disinfection was obtained after 30 minutes in Experiments 1 and 2, but after 60 minutes in Experiment 3. The disinfection in 30 minutes in Experiment 1 is attributed to the high average insolation during this experiment. While the average insolation in Experiment 2 was $17 \mathrm{Wh} / \mathrm{m}^{2}$ lower than that of Experiment 3, we believe that the fluctuations between low and high values in this experiment contributed to the shorter disinfection time (30 minutes) when compared to Experiment 3 in which total bacterial degradation occurred in 60 minutes.

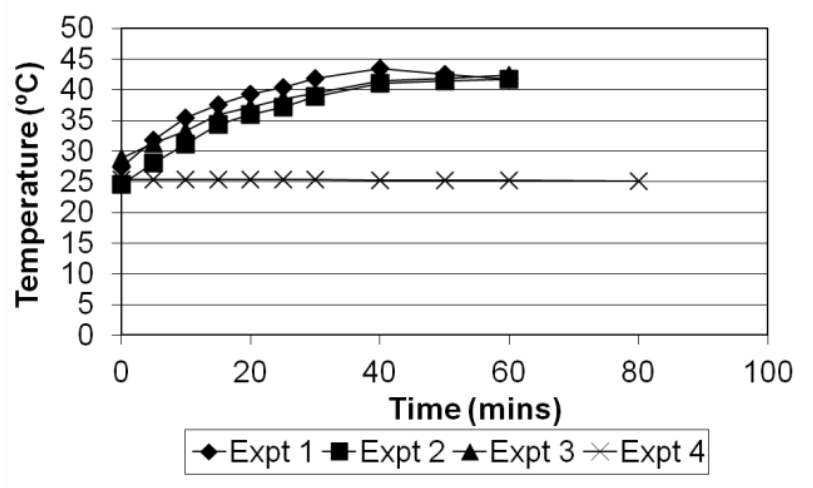

Figure 4 Reservoir temperatures for the four experiments

One component that plays a very important role in the photocatalytic degradation is the incoming ultraviolet light. On a clear day with little or no cloud cover the incoming ultraviolet light intensity would be higher than that obtained on a cloudy or overcast day. The ultraviolet light acting with the coating of titanium dioxide nanoparticles on the surface of the reactor enables the reactor to function even under overcast conditions. While the disinfection rate under overcast conditions may not be as rapid as under sunny conditions it is still far better than the six hours obtained under the SODIS conditions. During the night run there was no insolation and hence no ultraviolet light. Consequently there was no bacterial disinfection

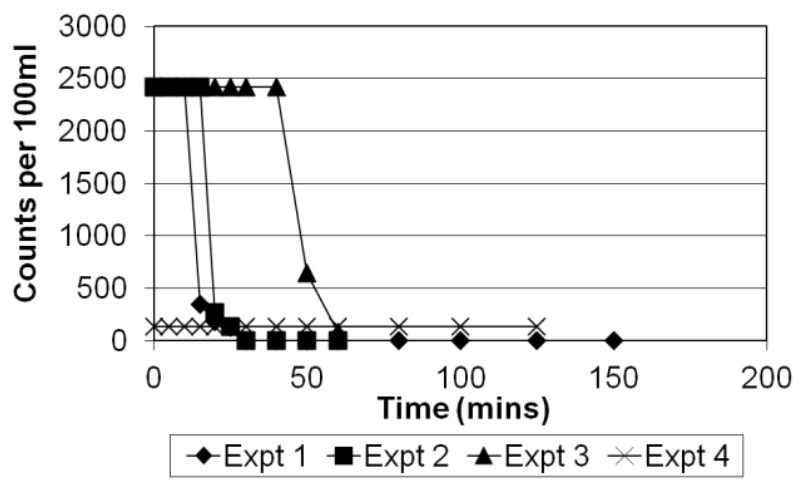

Figure 5. Bacterial decrease with time for the four experiments performed. 


\subsection{Experiments using the coated glass ballotini on plastic surface}

\subsubsection{Insolation values}

As indicated previously, four experiments were carried out using titanium dioxide on the glass ballotini as the active surface of the reactor. The insolation level as a function of time during the experiments is depicted in Figure 6. It varied between 446 and $250 \mathrm{Wh} / \mathrm{m}^{2}$ (Expt 5), 993 and 199 $\mathrm{Wh} / \mathrm{m}^{2}$ (Expt 6), 996 and $265 \mathrm{Wh} / \mathrm{m}^{2}$ (Expt 7) and 1018 and $889 \mathrm{Wh} / \mathrm{m}^{2}$ (Expt 8) for these experiments, which were all carried out during the daytime.

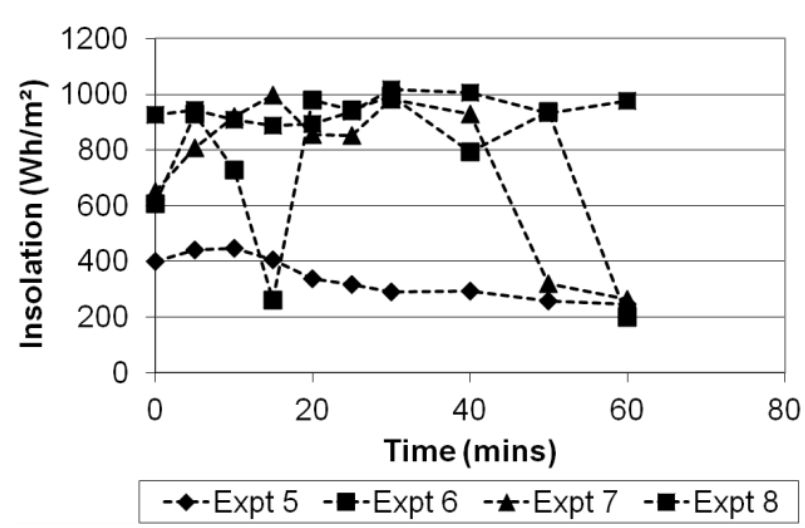

Figure 6. Insolation for the four experiments using the ballotini surface

\subsubsection{Reservoir temperatures}

The corresponding reservoir temperatures are shown in Figure 7 . The maximum reservoir temperature achieved over the one hour duration of these experiments was $43^{\circ} \mathrm{C}$ (Expt 6). This temperature and time duration is inadequate for completion of SODIS type activity which normally requires temperatures $>50^{\circ} \mathrm{C}$ for at least 4 hours.

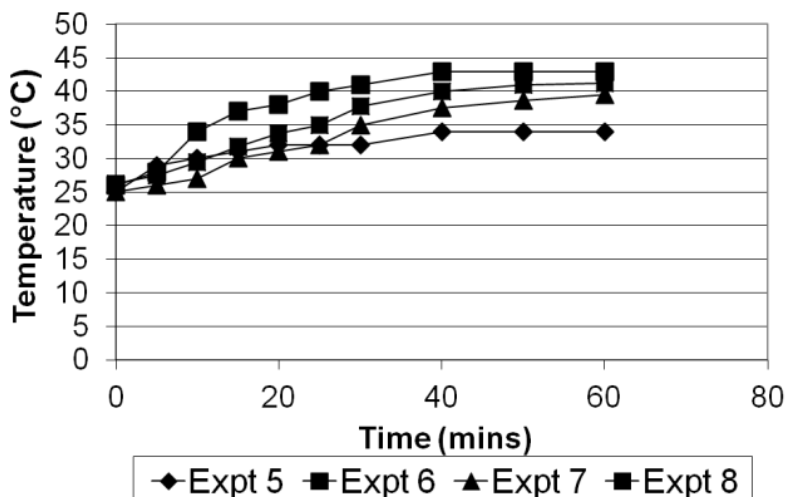

Figure 7. Reservoir temperature for the four experiments using the balotini surface

\subsubsection{Disinfection results}

Bacterial degradation for these experiments is shown in Figure 8. As can be seen degradation is very quick, total elimination occurring in 10 to 25 minutes depending on the solar conditions for all the starting bacterial concentrations. We attribute the quick disinfection compared to the SODIS method to the photocatalytic effect of UV in the presence of titanium dioxide. $\mathrm{TiO}_{2}$ is a catalyst that absorbs ultraviolet light from short wavelengths up to $385 \mathrm{~nm}$ and is known to be effective in solar detoxification [6]. Upon near UV irradiation, $\mathrm{TiO}_{2}$ generates electron/hole $\left(\mathrm{e}^{-} / \mathrm{h}^{+}\right)$pairs, according to Equation (1).

$$
\mathrm{TiO}_{2}+\mathrm{h} v \text {------ } \mathrm{TiO}_{2}\left(\mathrm{e}^{-}+\mathrm{h}^{+}\right)
$$

The latter can react with surface bound hydroxyl groups to generate hydroxyl radicals as shown in Equation (2).

$$
\mathrm{TiO}_{2}\left(\mathrm{~h}^{+}\right)+\mathrm{OH}^{-}
$$$$
\mathrm{OH}+\mathrm{TiO}_{2}
$$

The hydroxyl radicals then attack organic pollutants and initiate a series of oxidation reactions that ultimately lead to total mineralisation of the organic pollutants [7].

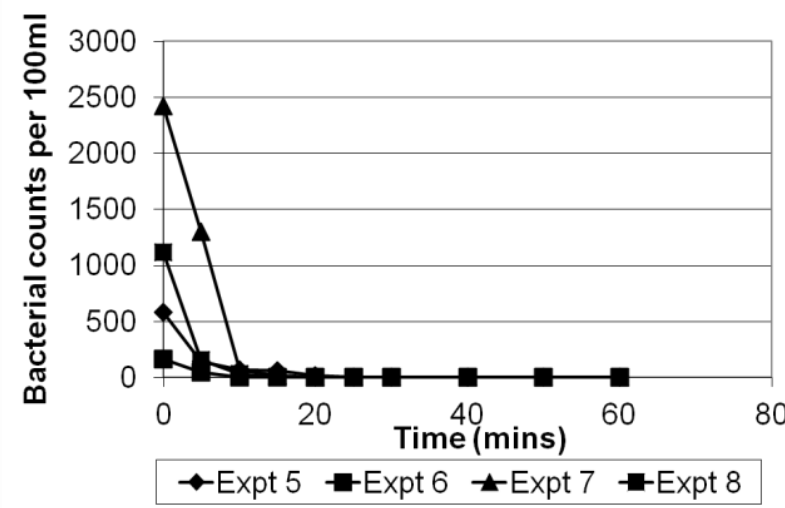

Figure. 8 Bacterial decay graphs for the four experiments using the ballotini surface 


\section{Conclusion and future work.}

The SODIS process takes 4-6 hours for bacterial decontamination. The reactor with the frosted glass and also the ballotini surface can complete the same task, purifying 10 litres of water in 10-30 minutes in most experiments. The newly developed plastic surface with the ballotini glass beads is flexible and inexpensive, providing the necessary surface area and excellent adhesion for the titanium dioxide nanoparticles. It is highly portable and has now provided us with an inexpensive photocatralytic surface to test various other contaminants that may be present in water.

\section{References}

[1] Magee, M., Ed. (2005). Healthy Waters. N.Y., Spencer books.
[2] Gordon , A. L. (2005). "The Climate System: Ocean Stratification."

from

http://eesc.1deo.columbia.edu/courses/ees/climate/lecture

[3] WHO/UNICEF, Ed. (2005). Water for life: making it happen, WHO Press.

[4] Sobsey, M. D. (2002). Managing water in the home: Accelerated health gains from improved water supply. Geneva, World Health Organisation

[5] Saunders, R., W. Mellows, et al., Eds. (2003). Application of SODIS Technology to rain and tap water samples from Mayaro, Trinidad and Tobago. Solar Disinfection of Water in Rural Communities of Latin America. ASO Project AE 141/2001.

[6] Linsebigler, A. L., G. Lu, et al. (1995). "Photocatalysis on $\mathrm{TiO} 2$ Surfaces: Principles, Mechanisms, and Selected Results." Chemical Reviews 95(3): 735-758.

[7] Nogueira, R. F. P. and W. F. Jardim (1996). "TiO2fixed-bed reactor for water decontamination using solar light." Solar Energy 56(5): 471-477. 